\title{
Enfrentando a violência contra a mulher na atenção primária à saúde
}

\author{
Facing violence against women in primary health care \\ Jovenildo Pinho da Silva Santos 1 \\ Thainan Alves Silva ${ }^{2}$ \\ Rita Luciene Silva Barreto ${ }^{3}$ \\ Clarice Moreira Portugal 4
}

\begin{abstract}
RESUMO
A violência contra a mulher configura-se como problema de saúde pública e violação de direitos humanos. Nesse estudo buscou-se relatar a experiência da implementação de um projeto de intervenção na área da saúde da mulher aplicado em uma Unidade de Saúde da Família localizada no interior da Bahia, por meio de ações educativas em saúde e capacitação profissional. Assim, discutiu-se a necessidade de formulação de estratégias que aperfeiçoem o atendimento às mulheres vítimas de violência na atenção primária à saúde, principalmente ações que fortaleçam a rede de atenção e de empoderamento dessas mulheres.
\end{abstract}

PALAVRAS-CHAVE: Violência Contra a Mulher. Atenção Primária à Saúde. Enfrentamento. Empoderamento.

\begin{abstract}
Violence against women is a public health problem and a violation of human rights. In this study, we sought to report the experience of implementing an intervention project in the area of women's health applied in a Family Health Unit located in the interior of Bahia, through educational actions in health and professional training. Thus, it was discussed the need to formulate strategies that improve the assistance to women victims of violence in primary health care, especially actions that strengthen the network of care and empowerment of these women.
\end{abstract}

KEYWORDS: Violence Against Women. Primary Health Care. Coping. Empowerment..

1 Médico. Especialista em Saúde Coletiva pelo Instituto de Saúde Coletiva da Universidade Federal da Bahia (ISC/UFBA). Salvador, Bahia, Brasil.

2 Enfermeira. Especialista em Enfermagem do Trabalho. Mestranda em Ciências da Saúde pela Universidade Estadual do Sudoeste da Bahia (UESB). Jequié, Bahia, Brasil.

3 Assistente Social pela Universidade Norte do Paraná (UNOPAR). Gandu, Bahia, Brasil.

4 Psicóloga. Mestre em Informação e Comunicação em Saúde. Doutora em Saúde Coletiva e Pós-doutora pelo Instituto de Saúde Coletiva da Universidade Federal da Bahia (ISC/UFBA). Salvador, Bahia, Brasil. 


\section{Introdução}

A violência vivenciada pelas mulheres em todo o mundo é considerada um problema de saúde pública (SCHRAIBER; D'OLIVEIRA; FRANÇAJUNIOR et al., 2007). Esse tipo de violência é identificado como violência de gênero, uma vez que está intimamente associada à condição de subordinação cultural da mulher perante a sociedade. Nessa perspectiva, é possível constatar que a violência contra a mulher pode ser caracterizada por agressão física, econômica, moral, sexual e psicológica, sendo sua forma mais corriqueira a executada por parceiros íntimos (MARINHEIRO; VIEIRA; SOUZA, 2006; SCHRAIBER; D'OLIVEIRA; FRANÇA-JUNIOR et al., 2007).

A problemática envolvendo essa discussão estimulou a criação e adoção de medidas de enfretamento da violência contra a mulher no âmbito nacional por meio da luta feminista atrelada à responsabilização estatal. Como exemplo disso, cita-se a elaboração e instituição, na década de 80, das Delegacias Especializadas ao Atendimento à Mulher (DEAMs) (SOUZA; CORTEZ, 2014). Além disso, outro marco importante no contexto da defesa às mulheres foi a promulgação, no ano de 2006, da Lei 11.340/06, também conhecida como "Lei Maria da Penha", que representa uma nova maneira de lidar com a questão da violência através da criação de uma rede de proteção e prevenção, atribuindo maior rigor às medidas punitivas e mais eficácia para as estratégias de prevenção à violência. (COUTO; ROCHA; RIBEIRO et al., 2018).

A Lei Maria de Penha, no âmbito jurídico e de proteção à mulher vítima de violência, é considerada uma das leis mais avançadas do mundo. A partir dela, inúmeras outras políticas públicas foram propostas e promulgadas no Brasil. Entretanto, na prática, observam-se desafios estruturais e de recursos humanos para a concretização das ações propostas (PEDROSA; ZANELLO, 2017; PASINATO, 2015). 
Apesar da implementação de leis e programas de proteção à mulher, alguns fatores vêm contribuindo para o déficit dessas ações como, por exemplo, quantitativo insuficiente de serviços especializados para atender a vítima e, também, a falta de preparo das equipes profissionais que estão na ponta do serviço oferecendo um atendimento insensível, com tendência à medicalização dos casos e a pouca ou nenhuma articulação entre os setores da sociedade. Somado a esse fator, ainda é possível constatar que a violência de gênero sofre uma invisibilidade social de uma maneira geral, principalmente quando é difundida a ideia de que a violência entre parceiros íntimos só deve ser resolvida pelos envolvidos (MARINHEIRO; VIEIRA; SOUZA, 2006; PASINATO, 2015).

Dessa forma, a construção de um atendimento em redes possibilita e facilita ações no tocante à proposta intersetorial, ou seja, a instituição desse cuidado articulado promove a legitimação de uma nova maneira de se fazer proteção social. Evidencia-se, então, que a estratégia do trabalho em rede no âmbito das políticas públicas configura-se como uma maneira de dividir demandas e responsabilidades entre as instituições (COUTO; ROCHA; RIBEIRO et al., 2018).

No que tange aos programas e leis desenvolvidos para proteger as mulheres, a baixa articulação da rede dificulta e/ou inviabiliza os encaminhamentos e as melhores condutas para cada caso, o que acarreta a falha no atendimento pleno da mulher vítima de violência de gênero. Tornase imprescindível compreender a violência contra as mulheres como um fenômeno altamente complexo, que suscita um tratamento específico para que haja controle e redução da sua incidência (COUTO; ROCHA; RIBEIRO et al., 2018).

Nesse contexto, é imperativo o esforço conjunto dos diversos órgãos para que a aplicação das políticas públicas seja realizada por ambas as partes, ou seja, tanto aqueles que propõem e fiscalizam as leis como os que ofertam o serviço propriamente dito. Dessa forma, propostas de articulações entre redes 
institucionais e ações intersetoriais tornam-se estratégias exemplares de ações voltadas para a temática da violência de gênero (PEDROSA; ZANELLO, 2017; COUTO; ROCHA; RIBEIRO et al., 2018).

Assim, é possível inferir que a violência contra as mulheres é um fenômeno complexo e polissêmico que, apesar das políticas de proteção à mulher voltadas para a sua diminuição, o que acontece na prática é a constatação frequente de novos casos. Desse modo, as ações de prevenção devem estar atreladas às políticas na área social e da educação, almejando à redução das diferenças de gênero. Somado a isso, é imperativo conhecer o perfil da violência doméstica para desenvolver ações sociais e de saúde voltadas para erradicação desse problema (AMARAL; VASCONCELOS; SÁ et al.,2016).

Nesse sentido, o estudo sobre essa temática se justifica pela necessidade de discussão constante sobre a eficácia (ou não) das estratégias de proteção às mulheres vítimas de violência, propostas pelas leis, uma vez que tem se observado aumento do número de casos de violência contra a mulher.

Todo esse contexto motivou o desenvolvimento, no âmbito da Atenção Primária à Saúde (APS), de um projeto de Intervenção que teve como objetivo central aperfeiçoar o acolhimento e a atenção às mulheres em situação de violência. Assim, o presente estudo tem como objetivo realizar um relato de experiência sobre a implementação desse projeto em Unidade de Saúde da Família (USF) em um município do interior da Bahia.

\section{Metodologia}

Estudo elaborado a partir da monografia "Enfrentando a violência contra a mulher no âmbito da Atenção Primária à Saúde", apresentada ao curso de especialização em Saúde Coletiva: Concentração em Atenção Básica -Saúde da Família do Programa de Pós-Graduação em Saúde Coletiva da 
Universidade Federal da Bahia (UFBA), Salvador -BA, Brasil, 2018, oferecida aos médicos contratados pelo Programa Mais Médicos do Governo Federal brasileiro.

Trata-se, portanto, de um estudo qualitativo, do tipo relato de experiência, desenvolvido a partir da execução do Projeto de Intervenção intitulado: Enfrentando a violência contra a mulher no âmbito da Atenção Primária à Saúde, em uma Unidade de Saúde da Família em um município do interior da Bahia, no período do mês de novembro do ano de 2018 ao mês de fevereiro do ano de 2019.

O desenvolvimento desse tipo de projeto faz parte das atividades dos profissionais que integram o Programa Mais Médicos. Assim, não houve necessidade do mesmo ser avaliado por um Comitê de Ética em Pesquisa (CEP), além disso, todas as atividades foram supervisionadas pela equipe do próprio Programa e pela equipe que coordena o curso de especialização em Saúde Coletiva, ao qual os profissionais também estão vinculados. Ressaltase, ainda, que foram respeitadas as disposições legais da Resolução do Conselho Nacional de Saúde nº 466/2012 (BRASIL, 2012).

A USF que serviu de lócus para a implementação do projeto está situada em zona rural, é composta por uma equipe, contendo médico e demais profissionais de saúde, como enfermeiro e técnicos em enfermagem, além de seis agentes comunitários de saúde. Na USF, são ofertados os atendimentos preconizados pelo Ministério da Saúde, tais como: atendimento de pré-natal, hiperdia, coleta de preventivo, puericultura, vacinação, procedimentos de enfermagem, educação em saúde nas mais diversas temáticas, dentre outros. Estão cadastradas nela cerca de três mil e quinhentas pessoas (3.500), sendo 150 crianças; 300 adolescentes; 1.500 mulheres e 600 homens com idades que variam de 18 a 97 anos.

Vale salientar que grande parte dessa população tem baixo grau de escolaridade, não possui renda fixa e vive da produção rural. Essas 
informações corroboram para a importância da execução de projetos com temas tão pertinentes como o da violência contra a mulher.

\section{Resultados e Discussão}

Para facilitar a implementação do Projeto de intervenção, umas das atividades propostas pela equipe do Programa da Especialização foi a construção de uma Matriz de Definição de objetivos e metas para nortear as ações a serem desenvolvidas. Nessa matriz estão descritos o objetivo geral, os objetivos específicos e as metas a serem alcançadas, como mostra a Figura 1:

Figura 1: Matriz de Definição de objetivos e metas

OBJETIVO GERAL: Aperfeiçoar o acolhimento e a atenção às mulheres em situação de violência usuárias de uma Unidade de Saúde da Família em um município do interior da Bahia.

\begin{tabular}{|c|c|}
\hline OBJETIVOS ESPECÍFICOS & METAS \\
\hline $\begin{array}{l}\text { Informar as usuárias do serviço } \\
\text { acerca das leis que amparam as } \\
\text { mulheres em situação de violência. }\end{array}$ & $\begin{array}{l}\text { - Dialogar com o maior número } \\
\text { de mulheres quanto aos seus } \\
\text { direitos perante as leis de } \\
\text { proteção social durante } \\
\text { consultas individuais e } \\
\text { discussões abertas à } \\
\text { comunidade. } \\
\text { - Encorajar mulheres vítimas } \\
\text { de violência a fazer as } \\
\text { denúncias durante consultas } \\
\text { individuais. } \\
\text { Acolher os casos de violência } \\
\text { contra a mulher que se } \\
\text { colocam enquanto demanda. }\end{array}$ \\
\hline
\end{tabular}




\begin{tabular}{|c|c|}
\hline $\begin{array}{l}\text { Orientar a equipe quanto às } \\
\text { condutas coerentes e humanizadas } \\
\text { em casos de violência contra a } \\
\text { mulher. }\end{array}$ & $\begin{array}{l}\text { - Capacitar os profissionais que } \\
\text { compõem a equipe de saúde da } \\
\text { família sobre a temática em } \\
\text { questão. } \\
\text { - Executar ações coerentes e } \\
\text { humanizadas frente a } \\
\text { situações de violência de } \\
\text { gênero. }\end{array}$ \\
\hline $\begin{array}{l}\text { Identificar os obstáculos que } \\
\text { impedem a eficácia das leis } \\
\text { destinadas à proteção plena e ao } \\
\text { acolhimento das mulheres vítimas } \\
\text { de violência no contexto específico } \\
\text { da comunidade em que a USF se } \\
\text { inserem. }\end{array}$ & $\begin{array}{l}\text { - Compreender o contexto } \\
\text { socioeconômico em que essas } \\
\text { mulheres estão inseridas. } \\
\text { - Minimizar ou erradicar } \\
\text { obstáculos que impedem a } \\
\text { implementação plena dessas } \\
\text { leis acolhimento } \\
\text { humanizado às mulheres } \\
\text { vítimas de violência. }\end{array}$ \\
\hline $\begin{array}{l}\text { Incrementar o diálogo em torno da } \\
\text { violência de gênero com a } \\
\text { comunidade. }\end{array}$ & $\begin{array}{l}\text { Realizar palestras e } \\
\text { discussões abertas a toda } \\
\text { comunidade (mulheres e } \\
\text { homens de todas as idades) } \\
\text { sobre a temática em questão. }\end{array}$ \\
\hline
\end{tabular}

Assim, a construção e implementação do projeto em relato permitiram a elaboração de dois eixos temáticos: "Fortalecimento da Rede de Atenção à mulher em situação de violência para consolidação do cuidado" e "Educação em saúde como estratégia de empoderamento". 


\section{Fortalecimento da Rede de Atenção à mulher em situação de violência para consolidação do cuidado}

Conforme explicitado na Matriz de Definição de objetivos e metas, o objetivo geral proposto no projeto de intervenção foi: aperfeiçoar o acolhimento e a atenção às mulheres em situação de violência usuárias de uma Unidade de Saúde da Família em um município do interior da Bahia. Para tanto, foram traçados alguns objetivos específicos a fim de alcançar esse objetivo geral, tais como: orientar a equipe quanto às condutas coerentes e humanizadas em casos de violência contra a mulher e identificar os obstáculos que impedem a eficácia das leis destinadas à proteção plena e ao acolhimento das mulheres vítimas de violência no contexto específico da comunidade em que a USF se inserem.

Deste modo, visando alcançar os seguintes objetivos específicos, foi extremamente necessário o aprimoramento teórico e epistemológico em torno do tema, de forma que o primeiro autor, responsável pela condução e implementação do projeto, matriculou-se em cinco cursos oferecidos pelo Sistema Universidade Aberta do SUS (UNA-SUS) que tratavam sobre a violência contra a mulher.

O UNA-SUS é coordenado pelo Ministério da Saúde (MS), através da atuação conjugada da Secretaria de Gestão do Trabalho e da Educação na Saúde (SGTES/MS) e da Fundação Oswaldo Cruz (Fiocruz), e oferece diversos cursos que são idealizados a partir da análise das necessidades da população, buscando soluções para os problemas de saúde pública. Os cursos ofertados são voltados para extensão, aprimoramento, especialização e mestrados profissionais, que abarcam diversos temas na área da saúde (BRASIL, 2010).

Nesse contexto, o mês de dezembro do ano de 2018 foi destinado para o aperfeiçoamento do responsável pela condução e implementação do projeto enquanto médico e profissional, tendo sido cursados e devidamente concluídos os seguintes cursos oferecidos pelo UNA-SUS: Violência por Parceiros 
Íntimos: Definições e Tipologias; Violência por Parceiro íntimo no Contexto Familiar; Violência por Parceiro Íntimo e Perspectiva Relacional de Gêneros; Políticas Públicas no enfrentamento da violência por parceiro íntimo; Rede de Atenção à Violência por Parceiro Íntimo. Todos os cinco cursos realizados totalizavam carga horária de trinta (30) horas cada e se enquadravam na categoria de curso de qualificação profissional.

A formação e o desenvolvimento dos profissionais que atuam na área da saúde, mediante cursos de capacitação, pós-graduação, etc. são essenciais e devem ocorrer de forma descentralizada, ascendente, transdisciplinar e continuada, promovendo o aprendizado e o compartilhamento de conhecimento pelos profissionais envolvidos. $\mathrm{O}$ intercâmbio com a equipe pensado a partir da lógica da educação permanente em saúde possibilita um melhor e eficaz desenvolvimento do trabalho em equipe, de modo a alcançar resoluções para os obstáculos existentes, a humanização da atenção ofertada e a melhora na qualidade do cuidado à saúde, culminando em benefícios para os envolvidos e para os usuários dos serviços (BRASIL, 2005).

Diante do exposto, após a finalização desses cursos, foi possível dar continuidade ao projeto dentro da USF com a capacitação da Equipe de Saúde da Família (EqSF) sobre os temas que se relacionavam com o atendimento da mulher vítima de violência. A primeira capacitação da equipe foi denominada "Reconhecendo as Políticas Públicas que amparam a mulher vítima de violência" e nela foram abordados temas como: Prevalência da violência contra a mulher; Fundamentos éticos e legais do atendimento a vítimas de violência; Violência Intrafamiliar; Portarias e Políticas específicas sobre o enfrentamento da violência contra a mulher; Condutas para o atendimento humanizado à mulher vítima de violência; dentre vários outros. Esse momento ocorreu no início do mês de janeiro do ano de 2019, teve duração de oito (8) horas e contou com a participação de 1 enfermeira, 1 técnica de enfermagem, 1 recepcionista e 3 agentes comunitários de saúde (ACS). 
Essa capacitação foi concebida e realizada com base na metodologia Roda de Conversa ( $\mathrm{RC}$ ), o que facilitou o compartilhamento de experiências, informações e esclarecimento de dúvidas. A RC é uma metodologia válida de produção e compartilhamento de conhecimento, uma vez que permite que os participantes expressem suas impressões, concepções e opiniões sobre o tema em discussão, possibilitando um trabalho de reflexão sobre as manifestações apresentadas pelo grupo (MELO; CRUZ, 2014). Nas RCs, é possível trabalhar com os discursos, que são compreendidos como individuais e sociais, e também com as probabilidades de trazer novos significados a eles, produzindo inúmeros sentidos que favorecem leituras distintas das experiências e conhecimentos que os profissionais têm do mundo e de si mesmos dentro do contexto da violência contra a mulher na sociedade atual (PAN, ZONTA, TOVAR et al., 2014).

Diante do supracitado, a realização da roda de conversa foi muito importante e possibilitou a interação da equipe e uma discussão muito rica acerca do conteúdo trabalhado. Foi observado que alguns dos profissionais que participaram tinham concepções errôneas sobre a temática e não conheciam grande parte do conteúdo abordado, como por exemplo: políticas existentes para amparar e cuidar da mulher vítima de violência, os tipos de violência que podem ocorrer, dentre várias outras. $\mathrm{Na}$ oportunidade, foram esclarecidas dúvidas, desmistificados conceitos equivocados, quebrados tabus que se relacionavam com essa temática e com isso informações relevantes emergiram para aperfeiçoar o acolhimento dessas mulheres USF.

A realidade dos serviços de saúde no tocante a esse tema ainda está aquém da ideal. Um dos grandes obstáculos identificados e pontuados pela literatura é o despreparo e/ou desqualificação dos profissionais de saúde para assistir de maneira adequada essas mulheres (PEDROSA; SPINK, 2011)

O que se observa na prática é que os currículos acadêmicos da área de saúde somados aos processos de formação no âmbito do trabalho não atendem às reais necessidades apresentadas por esse público tão peculiar. Além disso, 
ainda impera nos serviços a adoção do modelo biomédico, curativista e biologicista na formação do saber em saúde e na prática do cuidar. Diante desse cenário, reforça-se o conceito arcaico de saúde, principalmente quando não se permite usufruir da transversalidade ao se abordar temas como gênero, raça e classe social ao tratar do fenômeno da violência (PEDROSA; SPINK, 2011).

Nesse ínterim, a RC provocou a ampliação da competência crítica e reflexiva dos envolvidos sobre a temática em questão, que está atrelada a demandas históricas, sociais e de gênero, fatos que interferem diretamente na violência contra a mulher. A equipe conseguiu compreender que a violência é uma problemática complexa, multifatorial e de difícil manejo, relatando que em algumas situações ela é perceptível e em outras não é, suscitando decisões concretas a serem tomadas. Porém, foi possível absorver em seu discurso certa insegurança no tocante ao agir e em relação ao medo de interferir nessas situações e isso pode caracterizar um dos principais obstáculos para a verdadeira efetivação das políticas e estratégias que amparam a mulher vítima de violência.

A temática sobre violência é ampla e complexa, portanto, apenas uma capacitação não deu conta de abarcar todo conteúdo relevante para se contemplar os objetivos desse projeto. A segunda capacitação da equipe foi denominada "Fortalecendo a Rede de Atenção à mulher vítima de violência" e nela foram explanados temas como: a estratégia organizacional dos serviços e profissionais em rede na busca da ampliação da resolubilidade e da integralidade da atenção; a estruturação da rede de atenção às vítimas de violência; equipes de Atenção Básica, Núcleo de Apoio à Saúde da Família (NASF), Núcleo de Prevenção das Violências e Promoção da Saúde (NUPREVS), serviços de atenção especializada de Saúde Mental; portarias e políticas específicas sobre o enfrentamento da violência contra a mulher; Serviços da política de assistência social, Sistema de Justiça, Segurança Pública, Ministério Público, Centros de Referência de Assistência Social 
(CRAS) e Centros de Referência Especializada de Assistência Social (CREAS), entidades da sociedade civil e comunidade; dentre outros.

Assim como a primeira capacitação, esse momento teve duração de oito (8) horas, contando com a participação de 1 enfermeira, 1 técnica de enfermagem, 1 recepcionista e 3 ACSs.

Como o resultado da primeira capacitação foi positivo, a metodologia de Roda de Conversa (RC) foi mantida, facilitando ainda mais o compartilhamento de informações e elucidação de dúvidas. Para iniciar esse momento utilizou-se o vídeo: "Violência contra as mulheres: o que os profissionais de saúde têm a ver com isso?", que foi desenvolvido pelo Conselho Federal de Psicologia (2016).

$\mathrm{O}$ conhecimento sobre a rede de atenção à mulher vítima de violência pelos profissionais que atuam na atenção básica ainda é deficiente e esse é um dos fatores que interferem negativamente para a estruturação dessa rede intersetorial de atenção. Assim, a articulação intersetorial e a atenção disponibilizada pelos serviços são elementos que intervêm no enfrentamento da violência contra a mulher. Ambos os elementos guardam relação com o fortalecimento da rede de atenção a mulheres vítimas de violência.Portanto, o processo de encaminhamento requer conhecimento dos serviços e de suas atribuições, ou seja, exige um preparo do profissional para o reconhecimento da violência e/ou para o acolhimento e encaminhamento da mulher (MENEZES; LIMA; CORREIA et al., 2014).

Nesse contexto, a construção de redes de serviços para o enfrentamento da violência contra as mulheres configura-se como uma das estratégias mais eficazes e também desafiadoras para lidar com esse problema multifacetado, uma vez que tal rede fortalece as mulheres, amparando-as e encorajando-as em suas ações (HASSE; VIEIRA, 2014).

Capacitar a equipe quanto à rede de atenção disponível para amparar, acolher e proteger a mulher vítima de violência nos diversos âmbitos - da saúde, da assistência social ou da justiça -,configurou-se como umas das mais 
relevantes estratégias para consolidar as ações preconizadas pelo Ministério da Saúde no tocante a essa questão, uma vez que, quando o profissional da atenção básica à saúde está capacitado para atender essa demanda, o cuidado ofertado será de qualidade e, por conseguinte, todos os encaminhamentos necessários serão feitos para que essa mulher tenha os seus direitos garantidos.

Nessa perspectiva, a qualificação desses profissionais sobre violência contra a mulher contribui substancialmente para a melhoria da assistência ofertada. A reflexão e a discussão da prática assistencial, na perspectiva do gênero subsidia a adoção de condutas coerentes diante dessas situações por parte dos profissionais, fazendo com que os mesmos sejam resolutivos nesses casos (SILVA; PADOIN; VIANNA, 2015).

\section{Educação em saúde como estratégia de empoderamento}

Seguindo a Matriz de Definição de objetivos e metas, os outros objetivos específicos idealizados relacionavam-se com o empoderamento da comunidade, principalmente das mulheres usuárias da USF e daquelas vítimas de violência. Assim, dando continuidade às intervenções propostas pelo projeto, no mês de janeiro de 2019, aconteceu, na própria USF, a palestra educativa "Falando sobre a violência contra a mulher" destinada à troca de conhecimentos com a comunidade. Esse momento contou com a participação de 17 pessoas, sendo 14 mulheres com idades entre 35 e 60 anos e 3 homens com idades entre 45 e 62 anos. Para que essa palestra acontecesse da melhor forma possível toda EqSF se empenhou. Em tempo hábil, a comunidade foi informada sobre a palestra pelos ACS e no dia todos auxiliaram a organizar os materiais necessários para que a conversa com os usuários do serviço fluísse como o planejado.

As profissões da área da saúde têm o dever de valorizar os efeitos positivos das ações educativas, uma vez que essas práticas enriquecem e 
favorecem o desenvolvimento do trabalho e o processo de ensinoaprendizagem que é inerente às práticas de saúde. Assim, é sabido que o processo educativo colabora para que haja o fortalecimento das potencialidades de cada indivíduo, tanto em sua individualidade quanto em sua coletividade, culminando em uma maior na valorização da saúde e no exercício da cidadania (ORIÁ; GLICK; ALVES, 2005). É importante salientar que as ações educativas são ferramentas utilizadas pelo Programa de Saúde da Família, visando à capacitação da comunidade para atitudes de autocuidado e cuidado ao outro, e de enfrentamento do processo saúde-doença e outras condições (CERVERA; PARREIRA; GOULART, 2011).

Diante do supracitado, a realização desse momento educativo foi extremamente relevante para a comunidade, visto que esclareceu diversas dúvidas que permeavam a temática da violência contra mulher, tais como: os tipos de violência contra a mulher, as condutas a adotar em casos de violência na família e na comunidade, dentre outras, além de permitir a interação dos participantes e compartilhamento de experiências com a abertura do diálogo.

Para iniciar a discussão, reproduziu-se o vídeo "Violência contra a mulher: dados e definições”, que foi elaborado pelo Portal Politize (2017) e trouxe diversas informações essenciais para o entendimento da temática. Após esse momento, explanou-se o conteúdo sobre os diversos tipos de violência contra mulher e dados estatísticos a nível internacional, nacional e local. Ao final da palestra foi exibido o vídeo: "Violência contra a mulher", uma matéria exibida pelo Programa Fantástico no ano de 2012.

Como resultado, foi possível identificar diversos questionamentos e uma participação maciça de todos, o que permite a conclusão de que as informações corretas chegaram ao público. Isso pode culminar na disseminação de informações coerentes, maior número de mulheres vítimas de violência procurando o serviço de saúde e tendo o acolhimento necessário e maiores denúncias de casos de violência contra a mulher por parte de terceiros. Contudo, as contribuições palpáveis desse momento poderão ser 
vistas no decorrer do cotidiano de atendimentos da unidade e isso será refletido nos sistemas de informações de saúde, no atendimento prestado a essas mulheres, dentre outros.

Ao utilizar o diálogo aberto e empático, foi possível perceber a existência de uma carência acentuada de informações quanto aos tipos de violência. Por exemplo, era de conhecimento da audiência a caracterização da violência física, psicológica e sexual, contudo, não fizeram referência à violência patrimonial e moral como forma de agressão. Dessa maneira, no decorrer da discussão sobre os tipos de violência, foi necessário intervir para poder fazer essa explanação e diferenciação de cada tipo.

No decorrer da palestra também foi abordada a questão das relações de poder que ocorrem dentro de casa, em que o homem tenta exercer sua força e poder sobre a mulher, sujeitando-a a uma situação de impotência, fragilidade e vulnerabilidade. As discussões foram muito calorosas e proveitosas, pois a população tinha concepções errôneas sobre essa temática e muitos tabus ainda persistiam nas suas falas, como a seguinte frase: “... em briga de marido e mulher não se mete a colher...”. Questões de feminicídio, dados alarmantes do mundo, do Brasil e da Bahia sensibilizaram para essa problemática e sobre a importância da denúncia para a prevenção de mortes evitáveis.

Como o conteúdo que envolve essa temática é muito extenso e em apenas uma manhã não seria possível abarcar todos os assuntos, aconteceu outro momento com a comunidade para aprofundar ainda mais as informações referentes à violência contra a mulher.

A segunda palestra educativa para a comunidade, intitulada: "Conhecendo a rede de atenção à mulher vítima de violência" aconteceu no mês de fevereiro do ano de 2019 contando com a presença de 30 usuários da USF, sendo 22 mulheres com idades entre 25 e 70 anos e 8 homens com idades entre 35 e 55 anos.

Para iniciar esse momento, utilizou-se como recurso propulsor dos debates a reprodução do vídeo: "Violência contra a mulher - Rede Gazeta" 
(2018), publicado pela Aquatro Comunicação no ano de 2018; e do vídeo: "O MP Explica: Rede de Atenção às Mulheres em Situação de Violência", disponibilizado pelo Ministério Público do Estado da Bahia em 2013.

O déficit de conhecimento da população acerca desse assunto é gigantesco. Foi possível perceber que a comunidade entende que a mulher deve recorrer somente à justiça quando for vítima de violência. Eles não enxergam as instituições de saúde como serviços que podem promover proteção nesse sentido e a palestra educativa conseguiu desmistificar essa concepção equivocada sobre essa temática, além de esclarecer os direcionamentos que são dados dentro dos serviços quando existem denúncias de violência contra a mulher e quando essa mulher violentada é assistida tanto pelos setores da saúde, quanto pela justiça e assistência social.

Os resultados desta atividade foram positivos e por meio dela foi possível multiplicar a informação e levar a comunidade à reflexão, com objetivo de transformação social e autonomia dos sujeitos envolvidos, o que permitiu uma maior compreensão e importância do conhecimento acerca da temática em discussão, tanto para as mulheres quanto para os homens presentes.

É inquestionável que a estratégia da educação em saúde é uma das melhores formas para prevenção e combate à violência contra a mulher, pois utiliza informações para fortalecer e empoderar as mulheres em situação de vulnerabilidade ou vítimas da violência (PAZ; GALVÃO; LOPES et al.,2018).

A educação em saúde, nesse contexto, integra os saberes científico e o popular, permitindo aos envolvidos o desenvolvimento de visão crítica sobre a qualidade da assistência à saúde que lhes é ofertada, como por exemplo, em casos de violência contra a mulher. Nessa perspectiva, a prática da educação em saúde na APS torna-se uma ação essencial, pois possibilita a interação dos profissionais de saúde com a comunidade, fornecendo as informações necessárias para a adoção de novos hábitos e condutas de saúde que 
favorecem a prevenção e promoção da saúde, bem como a prevenção de agravos (RAMOS; ARARUNA; LIMA et al., 2018).

\section{Conclusão}

A violência contra a mulher configura-se como um tema de discussões relevantes na sociedade contemporânea e o desenvolvimento de atividades diferenciadas e inovadoras acerca dessa problemática apresentam-se como estratégias eficazes que culminam em uma oferta de cuidado integral, acolhedor e humanizado. A disseminação dos conhecimentos sobre a violência contra a mulher é extremamente importante tanto para os profissionais que atuam na atenção primária à saúde quanto para a comunidade que vivencia e presencia casos de violência desse tipo.

No que se refere às estratégias de enfrentamento da violência contra as mulheres, foi possível identificar diversas ações que podem subsidiar e fortalecer a rede de atenção às mulheres vítimas de violência mediante capacitações da Equipe de Saúde da Família e empoderamento da comunidade com educação em saúde.

Desse modo, conclui-se que a elaboração e implementação desse projeto de intervenção, visando, dentre outras coisas, a aperfeiçoar o acolhimento das mulheres vítimas de violência, foi extremamente relevante, uma vez que possibilitou o compartilhamento de informações pertinentes a fim de capacitar a equipe e informar a comunidade, possibilitando sanar dúvidas existentes sobre a temática em questão. Portanto, os objetivos propostos foram alcançados e já foi possível constatar uma melhora significativa no tocante ao acolhimento. Contudo, os resultados mais concretos da implantação desse projeto serão vislumbrados a longo prazo, como por exemplo, a constatação de dados numéricos no que concerne às notificações de casos de violência na comunidade. Vale ressaltar que a execução desse projeto será constante. 
O estudo, então, permitiu a discussão do processo de enfrentamento da violência contra a mulher sob a ótica do serviço de atenção primária, dos profissionais que atuam nela e da população assistida. No escopo dos nossos principais achados, destaca-se a necessidade de uma efetiva articulação intersetorial e de capacitação de seus profissionais voltadas para a adoção de condutas coerentes e implicadas, objetivando a atenção integral dessa mulher. Ou seja, aponta-se para a importância da gestão no processo de articulação intersetorial, a partir da viabilização da interação entre as mais diversas instituições que compõem a rede de atenção.

Além disso, mostra-se fundamental a expansão dos estudos sobre esse tema, com objetivo de discutir estratégias para o enfrentamento da violência, incluindo, o empoderamento das mulheres em situação de violência.

\section{Referências}

AMARAL, Luana Bandeira de Mello; VASCONCELOS, Thiago Brasileiro de; SÁ, Fabiane Elpídio de; SILVA, Andrea Soares Rocha da; MACENA, Raimunda Hermelinda Maia. Violência doméstica e a Lei Maria da Penha: perfil das agressões sofridas por mulheres abrigadas em unidade social de proteção. Rev. Estud. Fem. [online], v. 24, n. 2, p.521-540, 2016.DOI: < https://doi.org/10.1590/1805-95842016v24n2p521>. Disponível em: <http://www.scielo.br/scielo.php?pid=S0104026X2016000200521\&script=sci_abstract\&tlng=pt>. Acesso em: 27 mar 2020.

AQUATRO COMUNICAÇÃO. Violência contra a mulher - Rede Gazeta. 2018.Disponível em: <https://www.youtube.com/watch?v=XSPIhfF5BJk>. Acesso em: $15 \mathrm{dez} 2019$.

BRASIL. Ministério da Saúde. A educação permanente entra na roda: pólos de educação permanente em saúde -conceitos e caminhos a percorrer. Brasília: Editora do Ministério da Saúde. 2005.

BRASIL. Ministério da Saúde. UNA-SUS. 2010. Disponível em: $<$ https://www.unasus.gov.br/institucional/unasus>. Acesso em: 20 nov 2019.

BRASIL. Ministério da Saúde. Conselho Nacional de Saúde. Resolução n. 466, de 12 de dezembro de 2012. Aprova as seguintes diretrizes e normas regulamentadoras de pesquisas envolvendo seres humanos. Brasília (DF): Ministério da Saúde; 2012.

CERVERA, Diana Patrícia Patino; PARREIRA, Bibiane Dias Miranda;GOULART, Bethania Ferreira. (2011). Educação em saúde:percepção dos enfermeiros da atenção básica em Uberaba (MG). Ciência \& Saúde Coletiva,v. 16, Supl. 1, p. 1547-1554, 
2011. DOI: <https://doi.org/10.1590/S1413-81232011000700090>. Disponível em: <http://www.scielo.br/pdf/csc/v16s1/a90v16s1.pdf>. Acesso em: 20 mar 2020.

CONSELHO FEDERAL DE PSICOLOGIA.Violência contra as mulheres: o que os profissionais de saúde têm a ver com isso? 2016. Disponível em: $<$ https://www.youtube.com/watch?v=084Z58rI8rE>. Acesso em: $16 \mathrm{dez} 2019$.

COUTO, Vinicius Assis; ROCHA, Rafael Lacerda Silveira; RIBEIRO, Ludmila Mendonça Lopes; SILVEIRA, Andrea Maria. Intersetorialidade e ações de combate à violência contra a mulher. Revista Estudos Feministas, v. 26, n. 2; mar.2018. DOI: $<$ https://doi.org/10.1590/1806-9584-2018v26n245859>. Disponível em: $<$ http://www.scielo.br/scielo.php?pid=S0104-

026X2018000200221\&script=sci_abstract\&tlng=pt>. Acesso em: 20 mar 2020.

HASSE, Mariana; VIEIRA, Elisabeth Meloni. Como os profissionais de saúde atendem mulheres em situação de violência? Uma análise triangulada de dados. Saúde debate [online]. v.38, n. 102, p. 482-493. 2014. ISSN 0103-1104. DOI: $<$ https://doi.org/10.5935/0103-1104.20140045>. Disponível em: $<$ http://www.scielo.br/scielo.php?pid=S010311042014000300482\&script=sci_abstra ct\&tlng=pt>. Acesso em: 27 mar 2020.

MARINHEIRO, André Luis Valentini; VIEIRA, Elisabeth Meloni;SOUZA, Luiz de. Prevalência da violência contra a mulher usuária de serviço de saúde. Rev Saúde Pública, v. 40, n. 4, p. 604-10, 2006. Disponível em: $<$ http://www.scielo.br/scielo.php?script=sci_arttext\&pid=S0034$89102006000500008>$. Acesso em: 25 mar 2020.

MATÉRIA DO FANTÁSTICO. Violência contra a mulher. 2012.Disponível em: $<$ https://www.youtube.com/watch?v=rxm3tufdXvQ>. Acesso em: $20 \mathrm{dez} 2019$.

MELO, Marcia Cristina Henares de; CRUZ, Gilmar de Carvalho. Roda deconversa: uma proposta metodológica para a construção de um espaço dediálogo no ensino médio. Imagens da Educação, Maringá, v. 4, n. 2, p. 31-39, 2014.DOI: $<$ https://doi.org/10.4025/imagenseduc.v4i2.22222>. Disponível em: $<$ http://periodicos.uem.br/ojs/index.php/ImagensEduc/article/view/22222>. Acesso em: 22 mar 2020.

MENEZES, Paulo Ricardo de Macedo; LIMA, Igor de Souza; CORREIA, Cíntia Mesquita; SOUZA, Simone Santos; ERDMANN, Alacoque Lorenzini; GOMES, Nadirlene Pereira. Enfrentamento da violência contra a mulher: articulação intersetorial e atenção integral. Saúde Soc. São Paulo, v. 23, n. 3, p. 778-786, 2014.DOI: 10.1590/S0104-12902014000300004. Disponível em: $<$ http://www.scielo.br/scielo.php?script=sci_arttext\&pid=S010412902014000300778>. Acesso em: 23 mar 2020.

MINISTÉRIO PÚBLICO DO ESTADO DA BAHIA. O MP Explica: Rede de Atenção às Mulheres em Situação de Violência. 2013. Disponível em:<https://www.youtube.com/watch?v=Mu3BmAZcnLs>. Acesso em: $18 \mathrm{dez} 2019$. 
ORIÁ, Mônica Oliveira; GLICK, Doris F; ALVES, Maria Dalva S.Trends in breastfeeding research by Brazilian nurses. Cad Saúde Pública, v. 21, n. 1,p. 20-8, 2005. DOI: <https://doi.org/10.1590/S0102-311X2005000100003>. Disponível em:<http://www.scielo.br/scielo.php?script=sci_arttext\&pid=S0102-

311X2005000100003>. Acesso em: 27 mar 2020.

PAN, M.; ZONTA, G.; TOVAR, A.; MALLMANN, L.; CRUZ, A. C. Plantão Institucional: uma proposta de atuação da psicologia junto ao jovem universitário.In Ponencia presentada en el V Congreso Latino Americano de Psicología de laULAPSI, La Antigua Guatemala, Guatemala, Centro América. 2014.

PASINATO, Wânia. Oito anos de Lei Maria da Penha.: Entre avanços, obstáculos e desafios. Rev. Estud. Fem. [online]. v. 23, n.2, p. 533-545, 2015. DOI: http://dx.doi.org/10.1590/0104-026X2015v23n2p533.

PAZ, Camila Torres da; GALVÃO, Carine Ferreira; LOPES, Rafaela Fonseca; VIEIRA, Ritade Cássia Calfa.Violência contra mulher: Contribuições para a efetivação da assistência de enfermagem. Repositório Institucional: Escola Bahiana de Medicina e Saúde Pública. 2018. Disponível em: $<$ https://www.repositorio.bahiana.edu.br:8443/jspui/bitstream/bahiana/3397/1/ART IGO\%20atualizado\%20FINAL.pdf>. Acesso em: 27 mar 2020.

PEDROSA, Claudia Mara; SPINK, Mary Jane Paris. A violência contra a mulher no cotidiano dos serviços de saúde: desafios para a formação médica. Saúde \& Sociedade, São Paulo, v. 20, n. 1, p. 124-135, 2011.DOI: $<$ https://doi.org/10.1590/S0104-12902011000100015>. Disponível em: $<$ http://www.scielo.br/scielo.php?pid=S010412902011000100015\&script=sci_abstract\&tlng=pt>. Acesso em: 27 mar 2020.

PEDROSA, Mariana; ZANELLO, Valeska. (In)visibilidade da violência contra as mulheres na saúde mental. Psicologia: Teoria e Pesquisa; v. 32, mar.2017. DOI: $<$ https://doi.org/10.1590/0102-3772e32ne214>. Disponível em: $<$ http://www.scielo.br/scielo.php?pid=S010237722016000500213\&script=sci_abstra ct\&tlng=pt>. Acesso em: 27 mar 2020.

PORTAL POLITIZE. Violência contra a mulher: dados e definições. 2017. Disponível em :<https://www.youtube.com/watch?v=SLfF9aAntQU>. Acesso em: 22 dez 2020.

RAMOS, Carlos Frank Viga; ARARUNA, Raimunda da Costa; LIMA, Charlene Maria Ferreira de; SANTANA, Carmen Lúcia Albuquerque de; TANAKA, Luiza Hiromi. Práticas educativas: pesquisa-ação com enfermeiros da Estratégia de Saúde da Família. Revista Brasileira de Enfermagem, v. 71, n. 3,p. 1211-1218,2018. DOI: $<$ http://dx.doi.org/10.1590/0034-7167-2017-0284>. Disponível em: $<$ http://www.scielo.br/pdf/reben/v71n3/pt_0034-7167-reben-71-03-1144.pdf>. Acesso em: 26 mar 2020.

SCHRAIBER, Lilia Blima; D’OLIVEIRA, Ana Flávia P L.; FRANÇA-JUNIOR, Ivan; DINIZ, Simone; PORTELLA, Ana Paula; LUDERMIR, Ana Bernarda; VALENÇA, Otávio; COUTO, Márcia Thereza. Prevalência da violência contra a mulher por parceiro íntimo em regiões do Brasil. Rev. Saúde Pública, São Paulo, v. 41, n. 5, p. 
797-807, 2007.DOI: https://doi.org/10.1590/S0034-89102007000500014. Disponível em: <http://www.scielo.br/scielo.php?script=sci_arttext\&pid=S003489102007000500014>. Acesso em: 24 mar 2020.

SILVA,Ethel Bastos da; PADOIN,Stella Maris de Mello;VIANNA, Lucila Amaral Carneiro. VIOLÊNCIA CONTRA A MULHER E A PRÁTICA ASSISTENCIAL NA PERCEPÇÃO DOS PROFISSIONAIS DA SAÚDE. Texto Contexto Enferm, Florianópolis, v. 24, n. 1, p. 229-37, Jan - Mar, 2015. DOI: https://doi.org/10.1590/0104-07072015003350013. Disponível em: $<\mathrm{http} / / /$ www.scielo.br/pdf/tce/v24n1/pt_0104-0707-tce-24-01-00229.pdf>. Acesso em: 27 mar 2020.

SOUZA, Lídio de; CORTEZ, Mirian Beccheri. A Delegacia da Mulher perante as normas e leis para o enfrentamento da violência contra a mulher: um estudo de caso. Rev. Adm. Pública, Rio de Janeiro.v. 48, n. 3, p.621-639, maio/jun, 2014. DOI: $<$ http://dx.doi.org/10.1590/0034-76121141>. 